\title{
Uncertainty in Dam Failure Consequence Estimates
}

\author{
Martin W. McCann, Jr., a and Greg Paxson ${ }^{2}$ \\ ${ }^{1}$ Director, National Performance of Dams Program, Department of Civil and Environmental Engineering, Stanford University, USA \\ ${ }^{2}$ Principal, Schnabel Engineering, West Chester, PA, USA
}

\begin{abstract}
When performing risk analyses for flood studies or dam safety projects, it is common to use best estimates for flooding probability, the peak flood levels, and for damage from the flooding to estimate the "expected" value of economic consequences or fatalities. Typical practice does not consider the uncertainties (aleatory and epistemic) in various elements of the risk analysis, In risk analysis for dams, the failure to address uncertainties in the elements of the risk analysis can have important implications to; 1) understanding the distribution of consequences that can result from a dam breach, 2) level of confidence in the risk results, 3) potential area of inundation, the residences, infrastructure, and the population-at-risk, and 4) deriving a Bayesian estimate of the expected-value of losses from a dam breach. This paper includes an approach for estimating uncertainties and the effect of these uncertainties in the dam breach and inundation analysis and in the flood damage relationships on the estimate of flood damages. The aleatory and epistemic uncertainties in the frequency of dam failure, the dam breach and inundation analysis and in the flood damage assessment are explicitly propagated through the estimates of the frequency distribution on downstream consequences.
\end{abstract}

\section{Introduction}

The initial, formal call for the use of risk and decision analysis methods in dam safety in the United States was made in the Federal Guidelines for Dam Safety [1], prepared in 1979. In recent years the use of risk analysis methods has increased considerably and the development of tools and practices continues to evolve.

An objective of flood risk analysis as generally applied in water resources planning studies is to estimate the expected annual damages [2, 3]. This approach has been extended to dam safety risk studies, with the obvious addition of methods for evaluating the frequency of uncontrolled release of the reservoir. As generally practiced these methods do not consider the suite of aleatory and epistemic uncertainties that effect estimates of the flooding downstream from a dam breach and the estimate of economic consequences from flooding (direct damages).

In this paper, an example earth dam failure is illustrated, with specific attention to the approach to model uncertainties associated with two aspects of the analysis.

\section{Risk Analysis Framework and Focus of this Paper}

This section presents a framework for incorporating the uncertainties in the various elements of a risk analysis in estimating the frequency and consequences associated with the unsatisfactory performance of dam systems. As is common in risk analyses to support dam safety assessments, this paper will focus on the analysis of events involving uncontrolled release of the reservoir that occurs as a result of a dam breach.

In simple terms, the purpose of a risk analysis is to estimate the magnitude and frequency of occurrence of unsatisfactory consequences. In practice estimating the chances of some unpleasant outcome can be difficult. For instance, estimating the occurrence and magnitude of consequence can be compromised by a lack of data, limited understanding of a physical phenomenon (e.g., piping in embankment dams) and thus limited capacity to build physically-based models, or the ability to model the combination of events that lead to an unsatisfactory outcome.

To systematically identify and assess uncertainties it is useful to construct a framework or taxonomy to partition the types of uncertainty in terms of their effect on models and model parameters. Table 1 shows such a taxonomy for characterizing the sources of uncertainty and their type in the context of models and model parameters. The framework in Table 1 has a number of

\footnotetext{
$\overline{{ }^{a} \text { Corresponding author: mecann@jbaslc.best.vwh.net }}$
} 
benefits in developing and quantifying a risk model. First, it offers a guide to ensuring that all sources of uncertainty are identified. Second, it supports the characterization of uncertainties as aleatory or epistemic, which for many problems can be difficult to assess. Lastly, a clear framework and accounting of sources of uncertainty avoids double counting or failing to identify and count uncertainties.

\begin{tabular}{|l|l|}
\hline \multicolumn{2}{|c|}{ Modeling } \\
\hline \multicolumn{1}{|c|}{ Epistemic } & \multicolumn{1}{|c|}{ Aleatory } \\
\hline $\begin{array}{l}\text { Uncertainty about a model } \\
\text { and the degree to which it } \\
\text { can predict events. Model, } \\
\text { epistemic uncertainty } \\
\text { addresses the possibility that } \\
\text { a model may systematically } \\
\text { (but not necessarily } \\
\text { predictably), over- or under- } \\
\text { predict events/results of } \\
\text { interest (i.e., deformations). }\end{array}$ & $\begin{array}{l}\text { Aleatory modeling } \\
\text { variability is the variation } \\
\text { not explained by a model. } \\
\text { For instance, it is variability } \\
\text { that is attributed to elements } \\
\text { of the physical process that } \\
\text { are not modeled and, } \\
\text { therefore, represents } \\
\text { variability (random } \\
\text { differences) between model } \\
\text { predictions and } \\
\text { observations. }\end{array}$ \\
\hline \multicolumn{2}{|c|}{ Parametric } \\
\hline $\begin{array}{l}|c| \\
\text { Earametric epistemic } \\
\text { uncertainty is associated } \\
\text { with the estimate of model } \\
\text { parameters given available } \\
\text { data, indirect measurements, } \\
\text { etc. }\end{array}$ & $\begin{array}{l}\text { This uncertainty is similar to } \\
\text { aleatory modeling } \\
\text { uncertainty. However, this is } \\
\text { variability that may be due } \\
\text { to factors that are random, } \\
\text { but have a systematic effect } \\
\text { on model results. }\end{array}$ \\
\hline
\end{tabular}

Table 1. Taxonomy / Partitioning of Uncertainties

In a number of fields of engineering the evaluation and quantification of aleatory and epistemic uncertainties in risk analysis is well established [4]. For instance, in probabilistic seismic hazard analysis the evaluation of sources of aleatory and epistemic uncertainty is standard practice [5]. Similarly, risk analyses for nuclear power plants (including the evaluation of civil structures and typical mechanical and electrical equipment items) must include an evaluation of aleatory and epistemic uncertainties [6].

In this paper we focus on two issues of the risk analysis for dams as it relates specifically to the estimate of consequences. These are:

- Modeling the sources of aleatory and epistemic uncertainty in dam breach and inundation modeling,

- Modeling the sources of aleatory and epistemic uncertainty in estimating economic losses due to dam break floods (the flood damage model)

\section{Description of Dam and Downstream Hazard Area}

The dam is a zoned earth embankment with a maximum height of 46-m and the maximum depth of water at normal pool is about $43-\mathrm{m}$. The reservoir has a volume of
71.5 million $\mathrm{m}^{3}$ at normal pool. Typically, the reservoir is at or above normal pool about $75 \%$ of the year, within $1.5-\mathrm{m}$ of normal pool about $90 \%$ of the year, and within $3-\mathrm{m}$ of normal for more than $95 \%$ of the year. In this analysis, the variation in reservoir level is not considered; the reservoir is set a normal maximum level.

The area downstream of the dam varies in type of development, ranging from rural farmland near the dam to a major urban area located about $88 \mathrm{~km}$ downstream of the dam. The area at risk from a dam failure includes many residential structures, industrial and educational facilities, and businesses, particularly in the urban areas. The number of structures at risk from a "sunny day" dam failure is on the order of 200 to 800 , depending on the characteristics of the dam breach and the estimate of the area of inundation, which is a main focus of this paper.

\section{Dam Breach and Inundation Analysis}

This section summarizes the factors that influence flooding estimates from a dam breach analysis and how uncertainties are addressed in this analysis.

\subsection{Factors Influencing the Breach Hydrograph}

When a dam breach occurs the outflow and the inundation downstream depends on factors/parameters related to the details of the breach and the hydraulic characteristics of the downstream channel [7]. With respect to the breach, these include:

- Dam failure mode (e.g., embankment instability leading to overtopping, piping),

- Location of the breach along the embankment,

- Breach geometry, including the width, side slopes, and bottom elevation,

- Erodibility of the embankment materials,

- Time to failure (time it takes for the full breach to develop), and

- Reservoir volume at the time of the breach.

\subsection{Factors Influencing the Downstream Flooding and the Flood Hazard}

In terms of the estimate of the inundation that occurs downstream, factors that influence the travel time, depth of inundation, velocity of flow, and the flood hazard include:

- Pre-existing flow in the river at the time of the earthquake (varies with the time of the year),

- Channel and overbank characteristics (slope, geometry, roughness),

- Changes in channel and overbank conditions during the year (winter vs summer),

- Interaction between main and side channel flows,

- Tidal effects (where applicable),

- Effects of obstructions,

- Debris content,

- River icing, and

- Topography 
The assessment of downstream inundation is specific to the river channel and overbank conditions. Similarly, the evaluation of aleatory and epistemic uncertainties in predicting flood stages [8] is specific to these conditions. Estimates of the aleatory uncertainty in peak flood elevation levels can be as much as $0.6 \mathrm{~m}$ [8]. For streams or rivers that are not gaged (flows and flood stage data is not collected) the aleatory uncertainty may be greater. In addition there will be epistemic uncertainties that will impact the estimate of flood levels.

The flooding that could occur from a dam failure is carried out in the following steps:

1. The outflow hydrograph from a dam breach is estimated based on the characteristics of the dam, reservoir volume at the time, failure mode, and the breach parameters.

2. The breach outflow hydrograph is then routed downstream using a model of the river channel and overbank areas. This model is used to estimate discharge, flow velocities, and flood stages along the downstream reach.

In this analysis the U.S. Army Corps of Engineers HEC-RAS model [9] is used to compute the dam breach outflow and to route the flood downstream, including flood stage and flow velocities.

\subsection{Aleatory Flood Inundation Model}

The flood stage at downstream locations can be represented by the following relationship:

$$
S=g\left(R V, E R, B R, F M, C H, Q_{R}\right)+\varepsilon
$$

Where:

$g()=$ represents the dam breach and flood routing model

$R V=$ reservoir volume

$B R=$ breach characteristics (time to failure, failure mode, breach geometry, etc.)

$E R=$ embankment erodibility

$F M=$ dam failure mode

$\mathrm{CH}=$ downstream channel characteristics (slope, Mannings n, etc.)

$Q R=$ river flow at the time of the dam failure

$E=$ random term that models the variability in flood stages [8]

There are a number of sources of aleatory and epistemic uncertainty associated with estimating the downstream flooding; estimating the parameters of the dam breach, river channel response, the estimated breach outflow, the estimated flood stage, etc.

\subsection{Dam Breach and Inundation Epistemic Uncertainty Model}

To model the epistemic uncertainty in the estimate of the breach characteristics (breach bottom width and time to failure) alternative empirical models are considered and for each model an estimate of the epistemic uncertainty in the model parameters is taken into account. A logic tree was constructed to model these sources of epistemic uncertainty.

As a frame of reference, Table 2 the sources of aleatory and epistemic uncertainty that are considered in this analysis in estimating the downstream flooding for an uncontrolled release of the reservoir.

\begin{tabular}{|l|c|c|}
\hline \multirow{2}{*}{ Element of the Analysis } & \multicolumn{2}{|c|}{ Sources of Uncertainty } \\
\cline { 2 - 3 } & Epistemic & Aleatory \\
\hline Dam Breach Geometry & & \\
a. Breach Width & $\mathbf{X}$ & $\mathbf{X}$ \\
b. Time to Failure & $\mathbf{X}$ & $\mathbf{X}$ \\
c. All other parameters & -- & -- \\
$\quad$ at fixed values $(R V$, & & \\
$\left.F M, C H, Q_{R}\right)$ & & \\
\hline Flood Routing & Not & $\mathbf{X}$ \\
\hline
\end{tabular}

Table 2. Sources of Uncertainty in Dam Breach/Flooding Analysis

The epistemic uncertainty in the estimating breach is addressed by considering two empirical models; Froehlich [7] and Bowles, et al. [10]. The Bowles, et al. [10] analysis is an update of the $\mathrm{Xu}$ and Zhang [11] study. Table 3 summarizes the best estimate of the breach parameters for each model used in the analysis. The standard deviation corresponds to the aleatory variability in the parameter (e.g., breach bottom width) estimate. This is the variability in the estimate of the model parameters that is not explained by the best fit to the data. Each model is assigned a probability weight as shown in Table 3. To represent the uncertainty in the model parameters, three estimates of the mean value of each breach parameter was considered that correspond to the $0.05,0.50$ and 0.95 percentile estimates. Modeling the uncertainty in the mean of each breach parameter accounts for the parametric uncertainty in the empirical analysis. Each breach parameter is modeled using a truncated normal distribution that is defined by its mean (best estimate) and standard deviation (SD).

\begin{tabular}{|l|c|l|l|}
\hline \multicolumn{1}{|c|}{ Model } & Weight & $\begin{array}{c}\text { Bottom } \\
\text { Breach Width } \\
(\mathbf{m})\end{array}$ & $\begin{array}{c}\text { Time to } \\
\text { Failure (hrs) }\end{array}$ \\
\hline $\begin{array}{l}\text { Froehlich } \\
\text { [7] }\end{array}$ & 0.40 & $\begin{array}{l}\text { Mean: } 81.6 \\
\text { SD: } 39.7\end{array}$ & $\begin{array}{l}\text { Mean: } 1.15 \\
\text { SD: } 0.35\end{array}$ \\
\hline $\begin{array}{l}\text { Bowles, } \\
\text { et al. [10] }\end{array}$ & 0.60 & $\begin{array}{l}\text { Mean: } 34.4 \\
\text { SD: } 9.6\end{array}$ & $\begin{array}{l}\text { Mean: } 1.02 \\
\text { SD: } 0.86\end{array}$ \\
\hline
\end{tabular}

Table 3. Best Estimate Breach Model Parameters Used

Figure 1 shows the logic tree for modeling the uncertainty in the breach parameters. Each branch in the logic tree corresponds to an alternative analysis to quantify the aleatory uncertainty in the dam breach hydrograph (an alternative prediction of the breach characteristics). For each logic tree branch, a Monte Carlo simulation is carried out using the breach parameters defined on the branch. The Monte Carlo simulation was performed using the MCBreach external controller for HEC-RAS, developed by WEST Consultants [12]. The result of the simulation is a series 
of dam breach outflow hydrographs that quantifies the aleatory variability in breach outflow. The complete set of branches in the logic tree models the epistemic uncertainty in the estimate of the breach outflow. The aleatory uncertainty in the estimated downstream flood stages is determined by routing each outflow hydrograph and then conducting the hydraulic analysis to estimate flood stages. Once this routing is completed, a probability distribution on the peak flood stage (assumed to be normally distributed in this analysis) can be determined through the use of equation 1 , where $\varepsilon$ has a zero mean and a standard deviation of 1.0 feet [8].

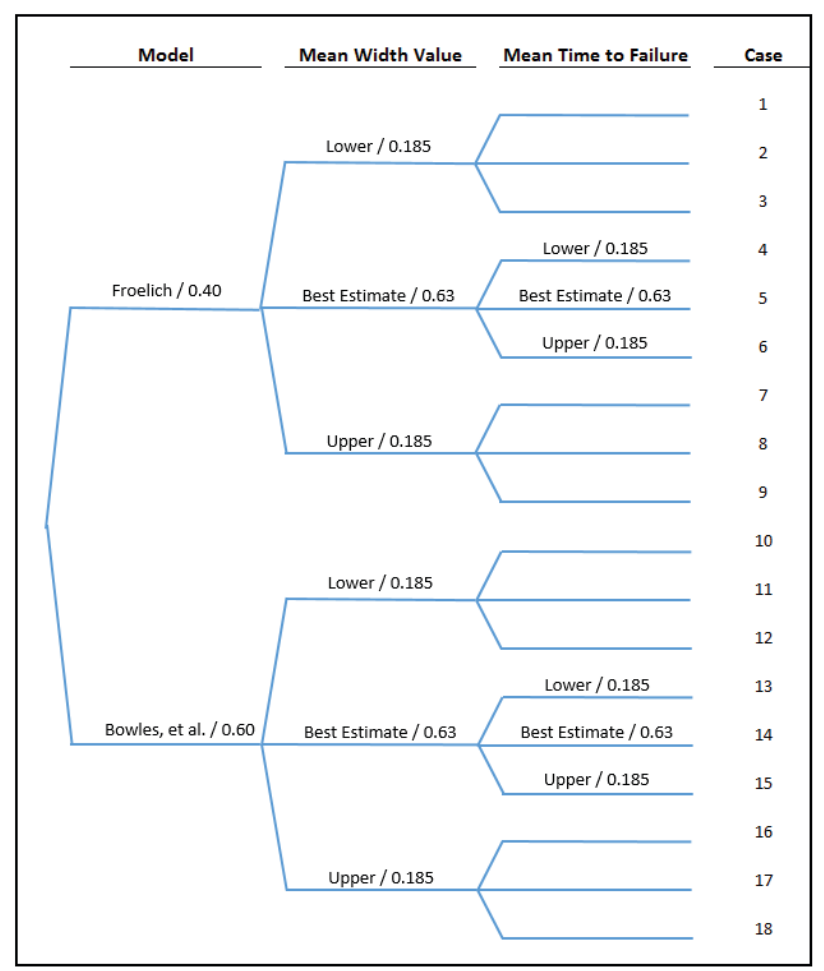

Figure 1. Logic tree for modeling the uncertainty in breach parameters used in this analysis.

Implementing the logic tree in Figure 1, there are 18 logic tree branches and thus different models for estimating the randomness or aleatory uncertainty dam breach parameters and in the breach outflow hydrograph. For each branch in the logic tree, a Monte Carlo simulation is performed.

\section{Flood Damage Model}

For decades, data on flood damage to structures and their content has been gathered [13]. For instance, this information is routinely collected by the National Flood Insurance Program (NFIP) as flood claims are received and processed. In term, these data are used to update empirical models. These models are the basis for NFIP estimates of expected annual flood damages and thus flood insurance rates [13]. In this section we describe sources of aleatory and epistemic uncertainty and factors that contribute to flood damage.

Figure 2 shows an example of expected flood damage curves for residential construction. Relationships like the one in Figure 2 are used in planning studies and in dam risk analysis studies to estimate economic losses; to transform flood hazard curves on flood stage to flood damage [2].

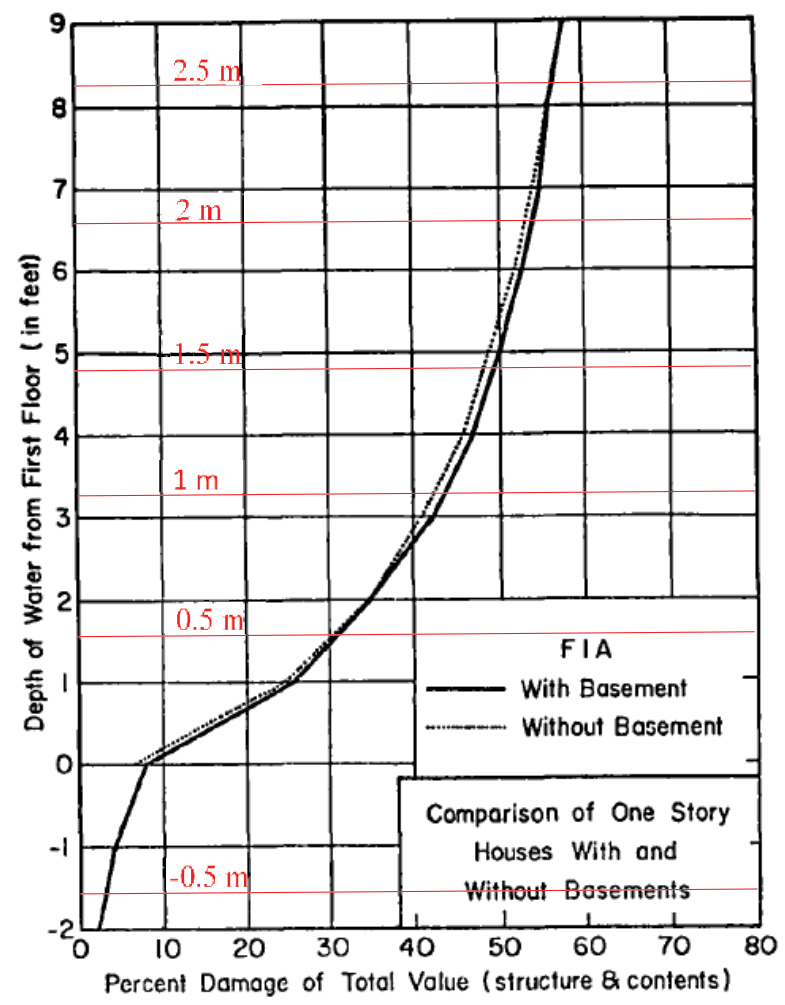

Figure 2. An example of an expected damage relationship for residential construction $[14,15]$.

A review of flood damage data and the results of statistical analysis of this data indicates there is considerable variability in flood damages as a function of peak flood depth. Figure 3 shows the mean and standard deviation of a recent compilation of NFIP flood damage data as well as the coefficient of variation of this data (the ratio of the standard deviation to the mean). The COV (see Figure 4) varies from about 0.20 to nearly 1.6 , with typical values above 0.6. An illustration of the variation in the flood damages that can occur for a given flood depth is shown in Figure 5 [13].

The scale of the COV and the distribution of observed flood damages levels suggests the use of the expected value to represent a distribution of the type shown in Figure 5 is a limited characterization of the flood damages that can occur and consequently the flood risk. 


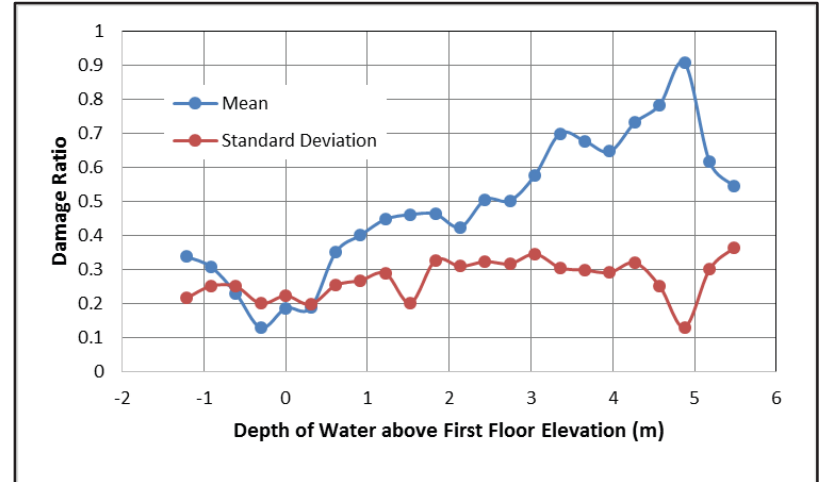

Figure 3. Illustration of the mean and standard deviation of flood damage ratio as a function of the depth of water above the first floor elevation for residential construction [13].

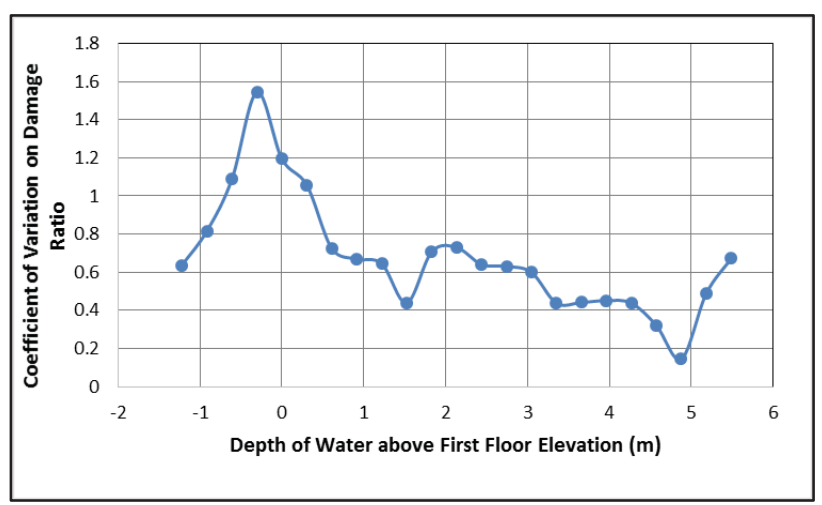

Figure 4. Illustration of the coefficient of standard deviation of flood damage ratio as a function of the depth of water above the first floor elevation for residential construction [13].

The size of the variation in flood damage may be indicative of a number of issues, such as the randomness in flood damage as characterized in terms of the peak depth of flooding, the variability in structure characteristics within general structure type categories. In addition, characteristics of flood events (and a contributor to the observed variance in reported claims) that may influence the nature and extent of flood damages that a structure and contents may experience [16, 17] include:

- Flow velocities

- Debris and impact loads

- Sediment load

- Buoyancy

- Scour effects

- Sour effects associated with levee failures

- Duration of inundation

- Contamination

- Erosion

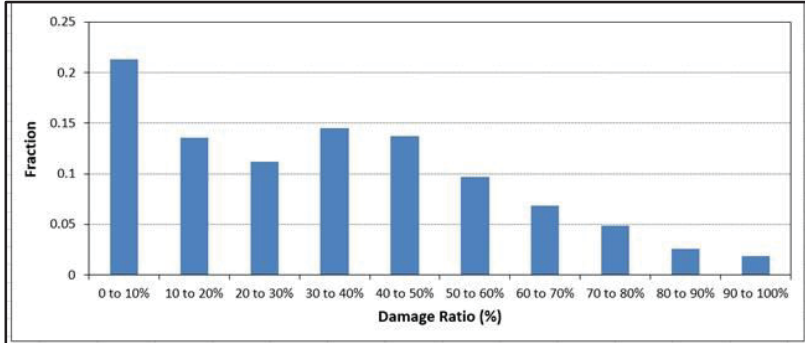

Figure 5. Variation in flood damage at $0.6 \mathrm{~m}$ of flooding. The chart shows the fraction of cases involving different levels of damage for the same level of flooding [13].

In addition, there may be variability between different flood events that produce the same peak flood depth on the same or different river systems.

While there is considerable flood damage data that is available and there is new data gathered every year as part of the NFIP, there are no known direct estimates of the epistemic uncertainty in flood damage models. The NFIP does make comparisons with Corps of Engineers flood damage estimates for similar structure types and develop a composite estimate of the mean flood damage.

\section{Consequence Estimates}

The dam breach simulations and flooding depths can be used to estimate downstream consequences from the dam failure.

\subsection{Dam Breach and Inundation Modeling Results}

For each branch in the logic tree 1,000 simulations were performed using the MCBreach model to estimate the aleatory uncertainty in the breach outflow hydrograph (a total of 18,000 simulations; 18 logic tree branches $\mathrm{x}$ 1,000 simulations per branch). Figure 10 illustrates the variation in the breach outflow hydrographs for Case 1 in the dam breach logic tree. In this case the peak discharge from the lowest to highest estimates varies by more than a factor of $3(14,732$ to 48,158 cumecs. In addition, the results in Figure 6 illustrate the variation in the shape of the hydrograph and the timing of the peak outflow.

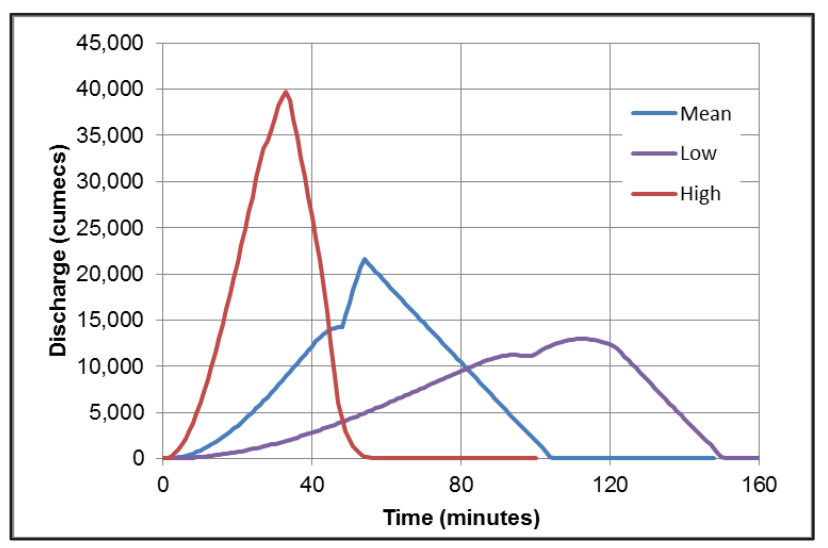

Figure 6. Case 1 variation in the outflow hydrographs from the dam breach; low, mean, and high estimates of the peak outflow discharge from the simulations. 
Figures 7 and 8 show the probability distributions on the peak outflow discharge (aleatory distributions) for 3 of the logic tree branches corresponding to the Froehlich and Bowles et al. model, respectively. Each probability distribution quantifies an estimate of the aleatory uncertainty in breach outflow (due to the randomness in breach characteristics) and the different distributions capture the epistemic uncertainty in the estimate of the breach outflows. Generally, for the cases presented, the Froehlich model results in higher estimates of outflow from the breach than the Bowles et al model. The cases presented for the Bowles et al. model have less uncertainty than the Froehlich model. Given these models are both empirical and their datasets are similar, the differences in the two models represent the uncertainty in estimating the character of a dam breach and this uncertainty is particularly important with respect to estimate the level of flooding downstream.

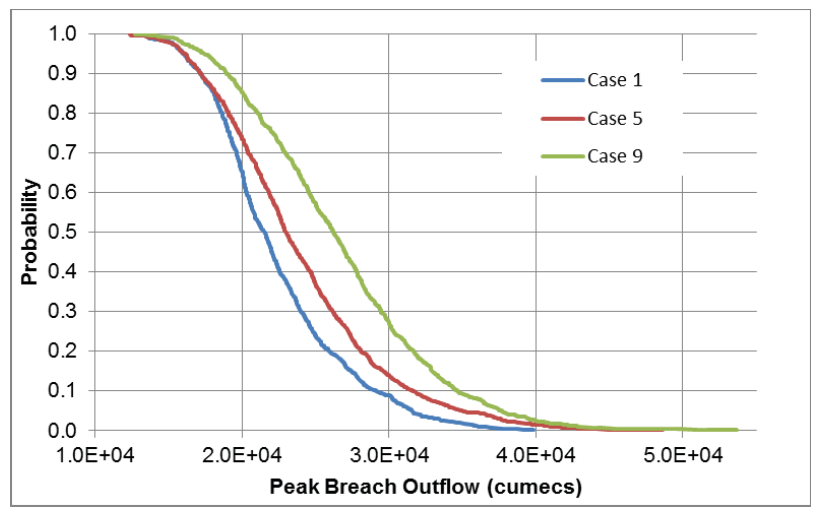

Figure 7. Cumulative distribution of peak outflows for selected dam breach logic tree branches using the Froehlich model.

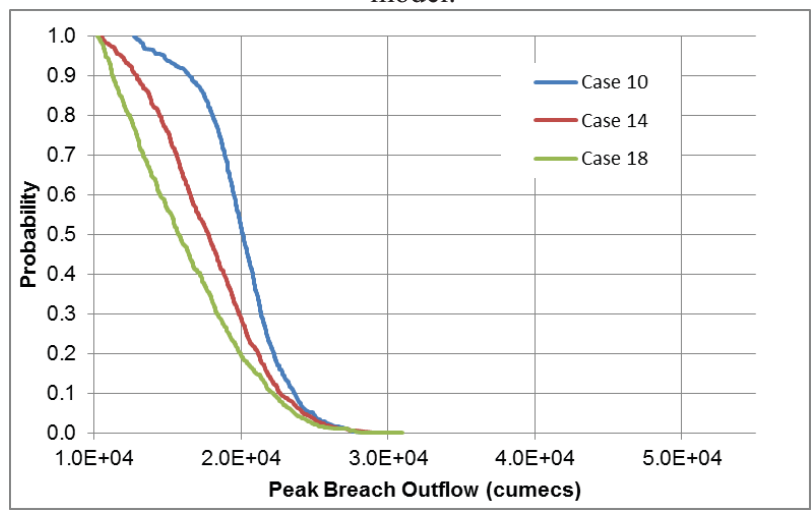

Figure 8. Cumulative distribution of peak outflows for selected dam breach logic tree branches using the Bowles et al model

The results of the dam breach analysis are input to a HEC RAS model of the river channel and overbank areas to estimate downstream flooding. These calculations are carried out for each of the eighteen sets of outflow hydrographs. The result is a corresponding set (18 in total) of probability distributions on the peak flood elevations. Figures 9 and 10 shows these results for 3 of the cases for the Froehlich model, at locations about 3 and $18 \mathrm{~km}$ downstream of the dam, respectively. For both models there is aleatory variability in the estimate of the peak flood levels that may occur downstream. As expected, the uncertainty is more significant at locations closer to the dam. For a location $3 \mathrm{~km}$ downstream of the dam, the range is nearly $5 \mathrm{~m}$, while at a cross section 18 $\mathrm{km}$ downstream, the range is about $0.3 \mathrm{~m}$.

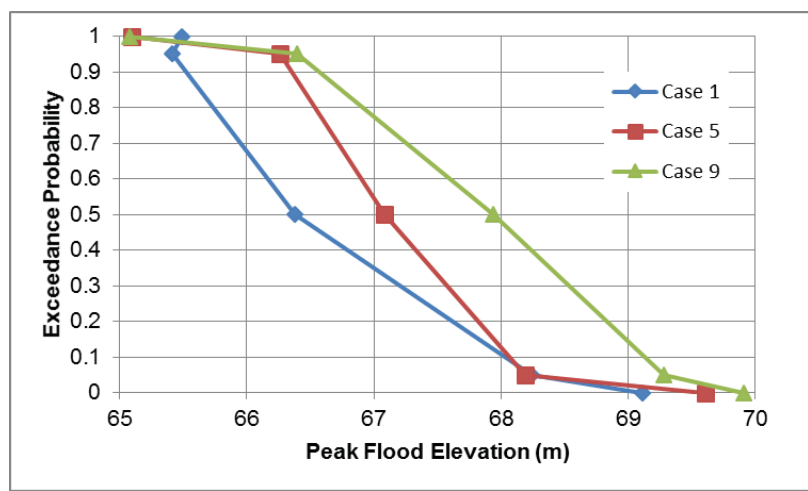

Figure 9. Cumulative distributions on the peak flood elevations selected cases of the Froehlich model at location about $3 \mathrm{~km}$ downstream of the dam.

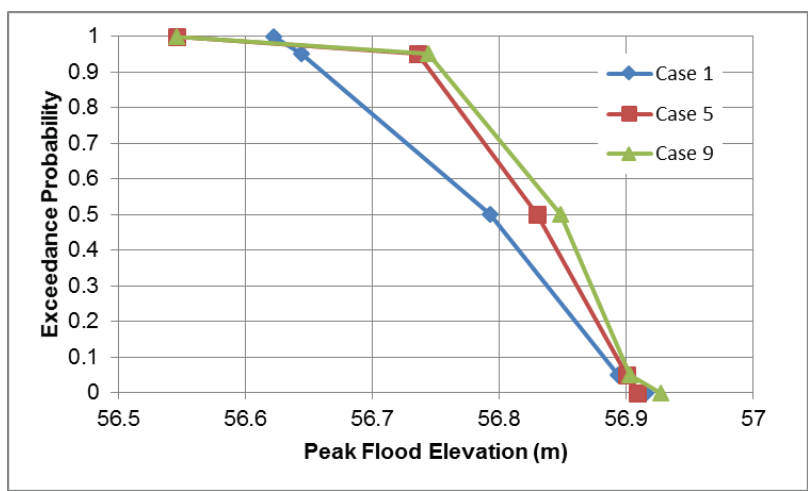

Figure 10. Cumulative distributions on the peak flood elevations selected cases of the Froehlich model at location about $18 \mathrm{~km}$ downstream of the dam.

\subsection{Estimating Life Loss Consequences}

Reclamation [18] has developed methods for estimating life loss for use in dam safety risk analysis. The method includes graphic relationships between Depth times Velocity (DV) and fatality rate. The fatality rate is multiplied by total pre-failure, non-evacuated population at risk (PAR) to obtain an estimated number of lives lost due to the flooding from the dam breach. Similar to the probability distributions for peak flood elevation, the HEC RAS model can be used to obtain a probability distribution for fatality rate at a given location. Figure 11 shows the result for 3 of the cases for the Froehlich model, at a location about $3 \mathrm{~km}$ downstream of the dam. This uses the upper suggested limit from Figure 2 [18], which is for cases for both "adequate" and "partial" warning.

The results shown in Figure 11 illustrate the uncertainty related to estimating fatality rate can range by a factor of nearly 3. Note that the fatality rate is multiplied by the PAR, which could also vary based on the downstream flooding levels (Figures 9 and 10). Finally, the fatality rate is usually expressed as a range from the lower to upper bounds from [18]; Figure 11 represents the upper bound only. 


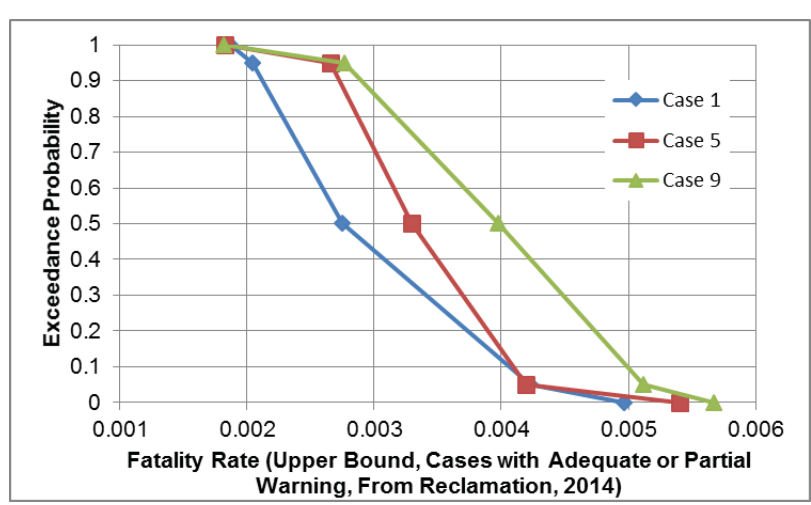

Figure 11. Cumulative distributions on the fatality rate from [18] (upper bound, cases with adequate or partial warning) for selected cases of the Froehlich model at location about $3 \mathrm{~km}$ downstream of the dam.

\subsection{Flood Damage Estimates}

To demonstrate the implementation of a Bayesian risk model, the assessment of economic consequences will be carried out for an individual reach in the inundation area where there is primarily residential construction. The objective is to demonstrate the contribution of different sources of aleatory and epistemic uncertainty to the risk results. Figure 12 shows the mean and standard deviation of the damage ratio for residential construction used in this analysis. This is a curve typical of what is used by the NFIP. It is a Bayesian estimate of the expected damage ratio using NFIP and USACE data.

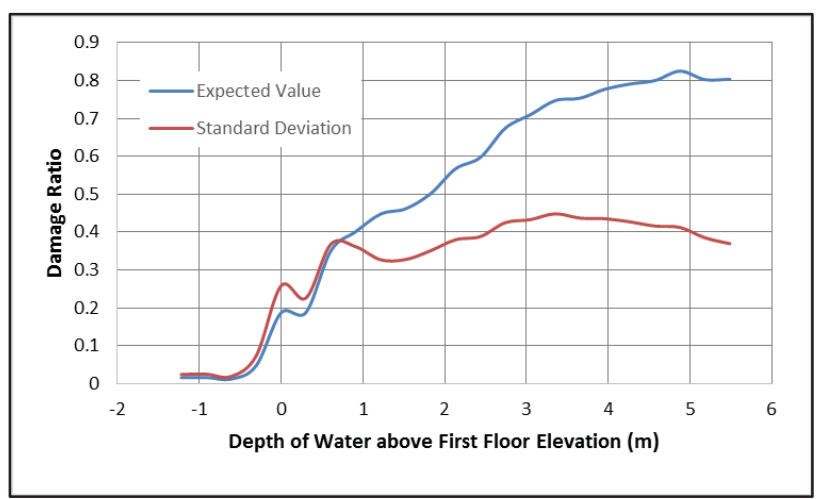

Figure 12. The mean and standard deviation of flood damage ratio as a function of the depth of water above the first floor elevation for residential construction used in the example risk calculations.

In this analysis, a flood damage model is used that accounts for the randomness (aleatory uncertainty) in flood damages based on the expected value and standard deviation of the flood damage ratio as derived from empirical data. Epistemic uncertainty is considered by assuming there is epistemic uncertainty in the estimate of the expected value mean damage ratio. As a means to assess the sensitivity of this uncertainty to the risk results, the uncertainty in the mean is assumed to be ten percent at the one standard deviation level. Three alternative estimates of the expected value of the damage ratio as a function of flood depth will be considered. These estimate will correspond to the $0.05,0.50$ and 0.95 estimates of the expected value, assuming a standard deviation of ten percent. In each of the three cases the coefficient of variation in the damage ratio is kept constant. Figure 13 illustrates this model for a flood depth of two foot above the first floor elevation.

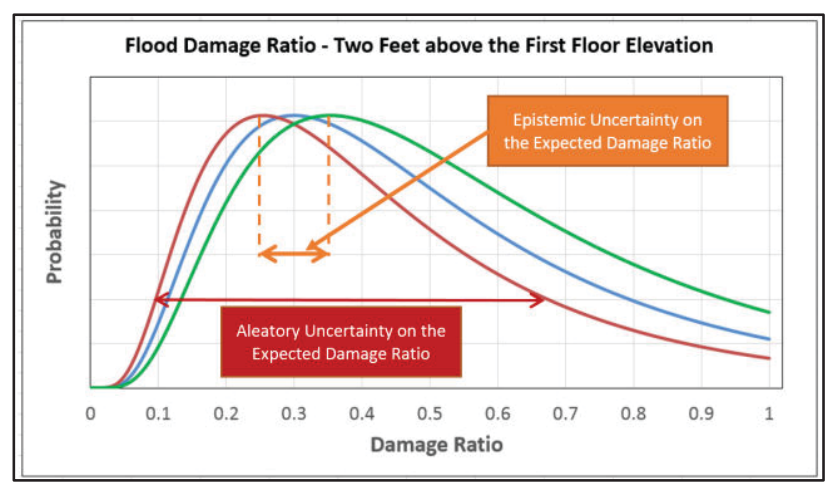

Figure 13. Illustration of the probability density function on the flood damage ratio for residential structures and flood depth of one feet above the first floor elevation.

\section{Summary}

The assessment of downstream risks due to dam failure involves a number of uncertainties. A framework for addressing these uncertainties is presented. A key element of the framework is the distinction that is made between different types of uncertainty and how they are incorporated in the risk analysis. In full Bayesian approach, the objective is to utilize all levels of information and evidence in assessing the outcomes that may occur, their frequency of occurrence and the level of confidence (certainty) that we have in these results. Typical risk analyses for dams do not explicitly address these uncertainties (aleatory or epistemic) as part of risk analysis. The implications of this can be important in some applications and likewise influence decision making. For instance, point estimates of risk do not full describe the scale of the consequences that may occur in the event of an uncontrolled release of the reservoir. Similarly, the failure to address epistemic uncertainties can lead biased estimates (low or high) of what is often referred as expected annual losses.

In this analysis, important contributors to the epistemic uncertainty in economic risk is the frequency of uncontrolled release of the reservoir. For the cases considered, the uncertainty in the flood damage and in the dam breach and inundation mapping are secondary contributors. However, the consideration of the aleatory uncertainty in economic risks is important in reporting the full distribution on economic risks that may occur.

In the case presented herein is a site-specific evaluation, both in consequence and uncertainty estimates could vary significantly. For example, the reservoir is not particularly large compared with the size of the river on which it is located (i.e. the river at the location of the dam has a contributing drainage area of over 5,000 square miles). This results in significant attenuation of the dam breach flood wave within a relatively short distance (about 10 miles) of the dam. Therefore, the uncertainty in consequence estimates may not be as significant at locations further downstream. For 
a larger reservoir or smaller river, the uncertainty could be significantly larger.

\section{Acknowledgement}

The authors acknowledge Chris Goodell of WEST Consultants who provided the MCBreach code used to perform Monte Carlo simulations within HEC-RAS, varying breach parameters to estimate outflow hydrographs.

\section{References}

1. Federal Coordinating Council for Science and Technology, (1979). "Federal Guidelines for Dam Safety," Washington, D.C.

2. U.S. Army Corps of Engineers, (1996). "Risk-Based Analysis for Flood Damage Reduction Studies," EM 1110-2-1619, Washington, DC.

3. National Research Council, (2000). "Risk Analysis and Uncertainty in Flood Damage Reduction Studies," prepared by the Committee on Committee on Risk-Based Analysis for Flood Damage Reduction, National Academies Press, Washington, D.C.

4. American Society of Mechanical Engineers/American Nuclear Society, (2013). "Addendum B to ASME/ANS RA-S-2008 Standard for Level 1/Large Early Release Frequency Probabilistic Risk Assessment for Nuclear Power Plant Applications".

5. U.S. Nuclear Regulatory Commission, (2012). "Practical Implementation Guidelines for SSHAC Level 3 and 4 Hazard Studies", NUREG-2117, Office of Nuclear Regulatory Research, Washington, DC.

6. EPRI, (1994). "Methodology for Developing Seismic Fragilities," Prepared by Jack R. Benjamin \& Associates, Inc. and RPK Structural Mechanics Consulting. TR-103959.

7. Froehlich, D.C. (2008). "Dam Breach Parameters and their Uncertainties," ASCE Journal of Hydraulic Engineering, Vol. 134, No. 12.

8. Xu, Y. and L.M. Zhang, (2009). "Breaching Parameters for Earth and Rockfill Dams," ASCE, Journal of Geotechnical and Geoenvironmental Engineering, pp. 1957-1970.

9. Bowles, D.S., Y. Xu, J.L. Ehasz, J.L. Briaud, and J.C. Ey, (2014). "Obtaining Reasonable Breach Hydrographs Based on Breach Parameter Estimates from Regression Methods," Proceedings of the Association of State Dam Safety Officials Conference, San Diego, CA.

10. Freeman, G.E. R.R. Copeland, and M.A. Cowan, (1995). "Quantifying Stage-Discharge Uncertainty at Gaging Stations", Proceedings of the First International Conference on Water Resources Engineering, San Antonio, TX. American Society of Civil Engineers, New York, NY.

11. National Research Council, (2015). "Tying Flood Insurance to Flood Risk for Low-Lying Structures in the Floodplain," prepared by the Committee on RiskBased Methods for Insurance Premiums of Negatively Elevated Structures in the National Flood Insurance Program, National Academies Press, Washington, D.C.

12. Hydrologic Engineering Center (HEC) (2010), "HEC -RAS," Version 4.1.0., U.S. Army Corps of Engineers, Davis, CA.

13. Goodell, C.R. (2013). "Moving Towards RiskInformed Dam Breach Modeling," Dam Safety 2013, Association of State Dam Safety Officials, September.

14. Grigg, N.S. and O.J. Helweg (1975). State-of-the-Art of Estimating Flood Damage in Urban Areas, Water Resources Bulletin, American Water Resources Association, Vol. 11, No. 2.

15. U.S. Federal Insurance Administration (1970). Flood Hazard Factors, Depth-Damage Curves, Elevation Frequency Curves, Standard Rate Tables.

16. McBean, E., Gorrie, J., Fortin, M., Ding, J., and Moulton, R. (1988). "Flood Depth-Damage Curves By Interview Survey." J. Water Resour. Plann. Manage., 114(6), 613-634.

17. Thieken, A.H., M. Mueller, H. Kkreibich, B. Merz, (2005). Flood damage and influencing factors: New insights from the August 2002 flood in Germany, Water Resources Research, Vol. 41.

18. U.S. Department of the Interior, Bureau of Reclamation (2014). "RCEM - Reclamation Consequence Estimating Methodology (Interim), Guidelines for Estimating Life Loss for Dam Safety Risk Analysis," February. 